\title{
Sinomenine inhibits A549 human lung cancer cell invasion by mediating the STAT3 signaling pathway
}

\author{
SHULONG JIANG ${ }^{1,2^{*}}$, YEBO GAO $^{1,3^{*}}$, WEI HOU ${ }^{1}$, RUI LIU $^{1}$, XIN QI $^{1}$, XIA XU $^{2}$, \\ $\mathrm{JIE} \mathrm{LI}^{2}$, YANJU BAO ${ }^{1}$, HONGGANG ZHENG ${ }^{1}$ and BAOJIN HUA ${ }^{1}$ \\ ${ }^{1}$ Department of Oncology, Guang'anmen Hospital, China Academy of Chinese Medical Sciences, Beijing 100053; \\ ${ }^{2}$ Department of Oncology, Jining First People's Hospital, Jining, Shandong 272111; \\ ${ }^{3}$ Beijing University of Chinese Medicine, Beijing 100029, P.R. China
}

Received March 19, 2015; Accepted April 8, 2016

DOI: $10.3892 / \mathrm{ol} .2016 .4768$

\begin{abstract}
Increasing evidence suggests that the failure of lung cancer treatment may occur as a result of tumor invasion and metastasis. Signal transducer and activator of transcription 3 (STAT3), an epithelial-mesenchymal transition-inducing transcription factor, is a key signaling molecule involved in the proliferation, apoptosis, invasion and metastasis of tumor cells. Sinomenine is an alkaloid compound with an antineoplastic potential against a variety of cancer cells. The aim of the present study was to assess the antitumor mechanisms of sinomenine in the A549 human lung cancer cell line. The results demonstrated that sinomenine manifested dose-dependent cytotoxicity and induced apoptosis in A549 cells. The protein expression of Janus kinase 2, STAT3, phosphorylated-STAT3, Snail, $\mathrm{N}$-cadherin and vimentin decreased in sinomenine-treated cells, while E-cadherin protein expression increased. The regulation of STAT3, N-cadherin and E-cadherin by sinomenine was further confirmed by reverse transcription-quantitative polymerase chain reaction and immunofluorescent staining. It was demonstrated that sinomenine exerts inhibitory effects on A549 human lung cancer cell invasion, possibly through the inhibition of STAT3 signaling. These results provide a novel insight into the role of sinomenine in the treatment of non-small cell lung cancer.
\end{abstract}

Correspondence to: Professor Baojin Hua, Department of Oncology, Guang'anmen Hospital, China Academy of Chinese Medical Sciences, 5 Beixiange Street, Beijing 100053, P.R. China E-mail: huabaojin@sohu.com

*Contributed equally

Key words: sinomenine, signal transducer and activator of transcription 3, epithelial-mesenchymal transition, lung cancer cell invasion

\section{Introduction}

Lung cancer is one of the most common types of malignant tumor with a high mortality (1). Although surgical resection is currently the optimal treatment for lung cancer, treatment of this disease remains challenging as patients have not demonstrated long-term clinical benefits (2). According to the recent International Database, following complete resection of lung cancer, the 5-year survival rate of patients with lung cancer is $73 \%$ for pathological stage IA, $58 \%$ for stage IB, $46 \%$ for stage IIA, $36 \%$ for stage IIB and $24 \%$ for stage IIIA (3). The failure of combined chemotherapy and surgical resection is primarily attributed to cancer metastasis and invasion $(4,5)$. Therefore, it is necessary to seek more effective anticancer agents targeting tumor invasion and metastasis.

Plants and other natural products are important chemical sources for chemotherapy $(6,7)$. Sinomenine is an active compound of the plant Sinomenium acutum, which has been widely used as traditional medicine in the treatment of various rheumatic diseases in China (8). It has been demonstrated that sinomenine has a number of pharmacological activities, including anti-inflammatory, antirheumatic, antiangiogenic and immunosuppressive effects $(9,10)$. Furthermore, there is strong evidence to suggest that sinomenine has antineoplastic potential against a variety of cancer cells, including synovial sarcoma, lung cancer and hepatocellular carcinoma (11-13).

Chronic inflammation is undeniably a contributing factor in tumour proliferation, survival, angiogenesis and metastasis (14-16). To date, the majority of studies investigating inflammation and cancer have focused on the regulatory network dominated by nuclear factor (NF)- $\kappa \mathrm{B}$ and signal transducer and activator of transcription 3 (STAT3) (17-19). STAT3 is a key molecule in the promotion of tumorigenesis, functioning via chronic inflammation, and also in the process of cancer-related inflammation, which is able to regulate the biological behavior of cancer and immune cells through mediation of extracellular signaling of inflammatory factors (18). Given the roles of STAT3 in chronic inflammation, and the regulation of the initiation and resolution of epithelial-mesenchymal transition (EMT) in malignant cells $(20,21)$, decreasing or blocking its activity may suppress malignant conversion. The present study hypothesized that 
sinomenine may be able to inhibit lung cancer invasion via modulation of the STAT3 signaling pathway; thus, the effect of sinomenine on STAT3 signaling and EMT biomarkers in A549 cells was investigated.

\section{Materials and methods}

Reagents. Sinomenine was obtained from the China's National Institute for the Control of Pharmaceutical and Biological Products (Beijing, China), and was dissolved in dimethyl sulfoxide (Sigma-Aldrich, St. Louis, MO, USA) as a stock solution. Cucurbitacin I, a potent pharmacological inhibitor of Janus kinase (JAK)/STAT3 was provided by Gene Operation (Ann Arbor, MI, USA).

Cell culture. The A549 human lung adenocarcinoma cell line was obtained from the General Medical Cell Center of Peking Union Medical College (Beijing, China). The cells were grown in RPMI-1640 medium (Invitrogen; Thermo Fisher Scientific, Inc., Waltham, MA, USA) supplemented with $10 \%$ inactivated fetal bovine serum (Sigma-Aldrich) and 1\% penicillin/streptomycin (Invitrogen; Thermo Fisher Scientific, Inc.), and incubated at $37^{\circ} \mathrm{C}$ with $5 \% \mathrm{CO}_{2}$.

Cell viability assay. Cell viability was analyzed in 96-well plates (Corning Incorporated, Corning, NY, USA) using Cell Counting kit-8 (CCK-8; Dojindo Molecular Technologies, Inc., Kumamoto, Japan). A total of $2 \times 10^{3}$ A549 cells/well were treated with the indicated concentrations of sinomenine or cucurbitacin I, which served as a positive control, for 24-72 h. Sinomenine was diluted by RPMI-1640 culture medium, and the final concentration was $0.125,0.25,0.5,1.0$ or $2.0 \mathrm{mM}$ in turn. The action concentration of cucurbitacin I was $0.25 \mathrm{uM}$. Following treatment, $20 \mu \mathrm{l} \mathrm{CCK-8} \mathrm{was} \mathrm{added,} \mathrm{and} \mathrm{incubation}$ continued for $1 \mathrm{~h}$. The optical density was determined at the wavelength of $450 \mathrm{~nm}$ on a multi-mode microplate reader (Synergy $^{\mathrm{TM}}$ HT; BioTek Instruments, Inc., Winooski, VT, USA).

Annexin V staining. Apoptosis was determined using an fluorescein isothiocyanate (FITC) Annexin V apoptosis DTEC KIT (BD Biosciences, Franklin Lakes, NJ, USA) according to the manufacturer's instructions. First, A549 cells were incubated with sinomenine for 24 and $48 \mathrm{~h}$. The cells were collected and washed twice with cold PBS and then resuspended in $1 \mathrm{X}$ Binding Buffer at a concentration of $1 \times 10^{6}$ cells $/ \mathrm{ml}$. Subsequently, $100 \mu \mathrm{l}$ of the suspension $\left(1 \times 10^{5}\right.$ cells) was transferred to a $5 \mathrm{ml}$ culture tube, and $5 \mu \mathrm{l}$ FITC-conjugated Annexin V with $10 \mu \mathrm{l}$ propidium iodide (PI) were added. The cells were gently vortexed and incubated for $15 \mathrm{~min}$ at $25^{\circ} \mathrm{C}$ in the dark. Finally, $400 \mu \mathrm{l}$ of $1 \mathrm{X}$ Binding Buffer was added to each tube and analyzed using the FACSCalibur ${ }^{\mathrm{TM}}$ flow cytometer and CellQuest Pro software version 6.0 (BD Biosciences) within $1 \mathrm{~h}$.

Western blotting. Western blotting was performed as previously described (22). Following treatment with sinomenine for $48 \mathrm{~h}$, A549 cells were lysed in radioimmunoprecipitation assay lysis buffer (Applygen Technologies, Inc., Beijing, China). The cell debris was removed by centrifugation $(15 \mathrm{~min}, 12,000 \mathrm{x} \mathrm{g}$; Eppendorf, Hamburg, Germany), and the supernatant was stored at $-80^{\circ} \mathrm{C}$. Protein concentrations were estimated using the Pierce BCA Protein Assay kit (Thermo Fisher Scientific, Inc.).

Cell lysates (20 $\mu \mathrm{g}$ per lane) were subjected to $12 \%$ sodium dodecyl sulfate polyacrylamide gel electrophoresis (Marker: Amresco, LLC, Solon, OH, USA; Electrophoretic and transfer equipment: Bio-Rad Laboratories, Inc., Hercules, CA, USA) and subsequently transferred to nitrocellulose membranes (EMD Millipore, Billerica, MA, USA). The membranes were blocked in 5\% skimmed milk, or bovine serum albumin (BSA; Vivantis Technologies, Oceanside, CA, USA) for phosphorylated proteins, in Tris-buffered saline with Tween $20(50 \mathrm{mM}$ Tris, $150 \mathrm{mM} \mathrm{NaCl}$ and $0.05 \%$ Tween 20 ), and serially incubated with primary antibodies at $4{ }^{\circ} \mathrm{C}$ overnight and secondary antibodies for $1 \mathrm{~h}$ at room temperature. The antibodies used were as follows: Rabbit monoclonal anti-JAK2 (dilution, 1:1,000; catalog no., 3230), anti-STAT3 (dilution, 1:1,000; catalog no., 12640), anti-phosphorylated (p)-STAT3 (dilution, 1:1,000; catalog no., 9145), anti- $\beta$-actin (dilution, 1:1,000; catalog no., 4970), anti-Snail (dilution, 1:1,000; catalog no., 3879), anti-vimentin (dilution, 1:1,000; catalog no., 5741), anti-E-cadherin (dilution, 1:1,000; catalog no., 3195) (Cell Signaling Technology, Inc., Danvers, MA, USA) and anti-N-cadherin (1:1,000; catalog no., 180224; Thermo Fisher Scientific, Inc.) antibodies, and horseradish peroxidase-linked anti-rabbit (catalog no., 7054) or anti-mouse (catalog no., 7076) immunoglobulin (Ig)G antibodies (dilution, 1:2,000; Cell Signaling Technology, Inc.). The bands were visualized using a chemiluminescence reagent (Applygen Technologies, Inc.) and recorded with a ChemiDoc ${ }^{\mathrm{TM}}$ XRS imaging system (Bio-Rad Laboratories, Inc.). The band densities were quantified using $\beta$-actin as a loading control, and analyzed using Image $\mathbf{J}$ (https://imagej.nih.gov/ij/).

Reverse transcription-quantitative polymerase chain reaction (RT-qPCR). The extraction of $5 \mathrm{mg}$ total RNA from the A549 cells was performed using TRIzol ${ }^{\circledR}$ reagent (Thermo Fisher Scientific, Inc.). The concentration and purity of the extracted RNA were determined with a NanoDrop ${ }^{\mathrm{TM}} 2000$ spectrophotometer (Thermo Fisher Scientific, Inc.), while electrophoresis was conducted to verify its integrity. A $2 \%$ agarose gel was used, the markers were supplied by Amresco, LLC, and the electrophoretic tank and visualization equipment were from Beyotime Institute of Biotechnology (Jiangsu, China).

To prepare the reaction master mix, $2 \mathrm{ml} 10 \mathrm{X}$ RT buffer, $4 \mathrm{ml} 25 \mathrm{mM} \mathrm{MgCl}_{2}, 2 \mathrm{ml} 0.1 \mathrm{M}$ dithiothreitol and $1 \mathrm{ml}$ RNAaseOUT were combined. The reaction mixture was added to the RNA/primer mixture, mixed briefly, and then incubated at room temperature for $2 \mathrm{~min}$. SuperScript II RT ( $1 \mathrm{ml} ; 50$ units) was added each tube, mixed and incubated at $25^{\circ} \mathrm{C}$ for $10 \mathrm{~min}$. Tubes were incubated at $42^{\circ} \mathrm{C}$ for $50 \mathrm{~min}$, heat inactivated at $70^{\circ} \mathrm{C}$ for $15 \mathrm{~min}$, and then chilled on ice. RNase $\mathrm{H}(1 \mathrm{ml})$ was added and incubated at $37^{\circ} \mathrm{C}$ for $20 \mathrm{~min}$. The first strand of complementary DNA (cDNA) was synthesized by RT using the High-Capacity RNA-to-cDNA kit (Thermo Fisher Scientific, Inc.) stored at $-20^{\circ} \mathrm{C}$ until use. qPCR was performed using TaqMan ${ }^{\circledR}$ Gene Expression Master Mix (Thermo Fisher Scientific, Inc.), template cDNA and primers. The primers were as follows: STAT3-RT5, 5'-CATCATGGG CTTTATCAGTAAGGA-3' and STAT3-RT3, 5'-GTCAAT GGTATTGCTGCAGGTCGT-3'; E-cadherin-RT5, 5'-CCC 
ACCACGTACAAGGGTC-3' and E-cadherin-RT3, 5'-CTG GGGTATTGGGGGCATC-3'; N-cadherin-RT5, 5'-GCG GAGAGGAAGACCAGGA-3' and N-cadherin-RT3, 5'-TAG TTGGGCTCCGAGTGCAT-3'; GAPDH forward, 5'-TGC ACCACCAACTGCTTAGC-3 and reverse, 5'-GGCATGGAC TGTGGTCATGAG-3'.

To prepare the mixture, $12.5 \mathrm{ml}$ SYBR Green Mix (2X), $0.2 \mathrm{ml} \mathrm{cDNA}, 1 \mathrm{ml}$ primer pair mix ( $5 \mathrm{pmol} / \mathrm{ml}$ each primer) and $11.3 \mathrm{ml} \mathrm{H}_{2} \mathrm{O}$ were combined. The total volume of each combined reaction mixture was $20 \mu \mathrm{l}$. Gene-specific, fluorogenic RT-qPCR for STAT3, E-cadherin, N-cadherin and glyceraldehyde 3-phosphate dehydrogenase was performed using a 3PrimeX Progene thermal cycler (Techne; Bibby Scientific Limited, Stone, UK). The thermocycling protocol was as follows: $50^{\circ} \mathrm{C}$ for $2 \mathrm{~min}, 1$ cycle; $95^{\circ} \mathrm{C}$ for $10 \mathrm{~min}$, $1 \mathrm{cycle} ; 95^{\circ} \mathrm{C}$ for $15 \mathrm{sec}, 60^{\circ} \mathrm{C}$ for $30 \mathrm{sec}$ and $72^{\circ} \mathrm{C}$ for $30 \mathrm{sec}$, 40 cycles; then $72^{\circ} \mathrm{C}$ for $10 \mathrm{~min}, 1$ cycle. The results were normalized according to the method by Liu et al (23). The ABI Prism SDS 7300 (Thermo Fisher Scientific, Inc.) was used for quantification and the results were viewed and analyzed with Applied Biosystems 7500 Fast system (Thermo Fisher Scientific, Inc.). The assay was repeated 3 times.

Immunofluorescence. A549 cells were treated with $1.0 \mathrm{mM}$ sinomenine for $24 \mathrm{~h}$ and then fixed in $4 \%$ paraformaldehyde (Santa Cruz Biotechnology, Inc., Dallas, Texas, USA) for $20 \mathrm{~min}$ at room temperature. The samples were washed 2 times in phosphate-buffered saline (PBS) to remove residual paraformaldehyde. Cells were permeabilized with $0.1 \%$ Triton X-100 made in PBS solution for $15 \mathrm{~min}$, and then washed 3 times with PBS. Subsequent to blocking with $2 \%$ BSA for $1 \mathrm{~h}$, cells were washed with PBS and BSA prior to being incubated with anti-STAT3 (1:500), anti-E-cadherin (1:500), anti-N-cadherin (1:500) or anti-vimentin (1:500) primary antibodies overnight at $4^{\circ} \mathrm{C}$. Samples were then washed 5 times with PBS and BSA, followed by incubation with anti-rabbit or anti-mouse $\mathrm{IgG}$ secondary antibodies for $1 \mathrm{~h}$ at room temperature. Cells were then stained with 4',6-diamidino-2-phenylindole (Santa Cruz Biotechnology, Inc.) and mounted with anti-fading agent. Immunostaining was analyzed using the widefield high-content screening system ImageXpress ${ }^{\circledR}$ Micro XLS (Molecular Devices, LLC, Sunnyvale, CA, USA).

Statistical analysis. All experiments were performed three times unless otherwise stated, and data are presented as the mean \pm standard deviation. Statistical significance was evaluated using one-way analysis of variance, followed by Fisher's least significant difference test. $\mathrm{P}<0.05$ was considered to indicate a statistically significant difference. All statistical analyses were performed using SPSS software version 18.0 (SPSS, Inc., Chicago, IL, USA).

\section{Results}

Sinomenine reduces A549 cell viability. To determine the effect of sinomenine on A549 cell viability, cells were treated with various concentrations of sinomenine $(0-2 \mathrm{mM})$ for 24-72 $\mathrm{h}$. The results demonstrated that sinomenine-treated cells exhibited a decreased cell count compared with untreated cells, and the inhibitory effect was dose-dependent (Fig. 1). As a positive

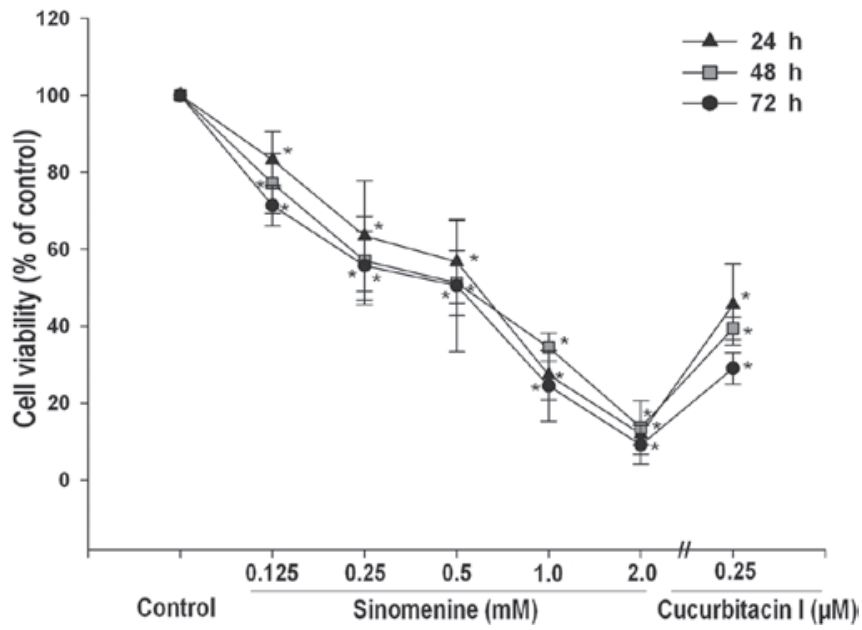

Figure 1. Effect of sinomenine on the viability of A549 cells. Cells were treated with 0-2 mM sinomenine or 0.25 uM cucurbitacin I for 24-72 h. Cell viability was analyzed using a colorimetric kit. Data are expressed as the mean \pm standard deviation $(\mathrm{n}=3),{ }^{*} \mathrm{P}<0.05$ vs. untreated vehicle control.

control, cucurbitacin I $(0.25 \mu \mathrm{M})$ was used, which significantly reduced the number of A549 cells $(\mathrm{P}<0.05)$ (Fig. 1).

Sinomenine induces A549 cell apoptosis. To determine whether the decreased viability of A549 cells following sinomenine treatment occurs as a result of apoptosis, Annexin V-FITC/PI staining was performed. As presented in Fig. 2A, sinomenine induced apoptosis in a dose- and time-dependent manner in A549 cells. The minimum dose of sinomenine required to induce apoptosis was $0.25 \mathrm{mM}$, while $1 \mathrm{mM}$ sinomenine produced a similar effect to that caused by $0.25 \mu \mathrm{M}$ cucurbitacin I (Fig. 2B and C). These results suggest that sinomenine-induced apoptosis may result in decreased cell viability.

Sinomenine regulates the protein expression of JAK2, STAT3 and EMT markers. To investigate the mechanisms underlying the biological effects of sinomenine on A549 cells, the upstream and downstream targets of STAT3 signaling were examined in A549 cells treated with sinomenine for $48 \mathrm{~h}$ by western blotting. The results demonstrated that sinomenine and cucurbitacin I downregulated the expression of JAK2, STAT3, p-STAT3, Snail, N-cadherin and vimentin compared with the untreated controls, while E-cadherin expression was upregulated (Fig. 3).

To further confirm the effect of sinomenine on the STAT3 signal transduction pathway, the messenger (m)RNA expression of STAT3, E-cadherin and N-cadherin was examined by RT-qPCR. The results demonstrated that the mRNA levels of STAT3 and N-cadherin were significantly reduced in the A549 cells following treatment with sinomenine and cucurbitacin I, whereas the level of E-cadherin mRNA was markedly increased $(\mathrm{P}<0.05)$ (Fig. 4). These results indicate that sinomenine may interfere with EMT in A549 cells by reducing the expression levels of the functional targets of the STAT3 signal transduction pathway.

Sinomenine prevents the invasion of A549 cells. To examine whether sinomenine affects the invasion of A549 cells, 


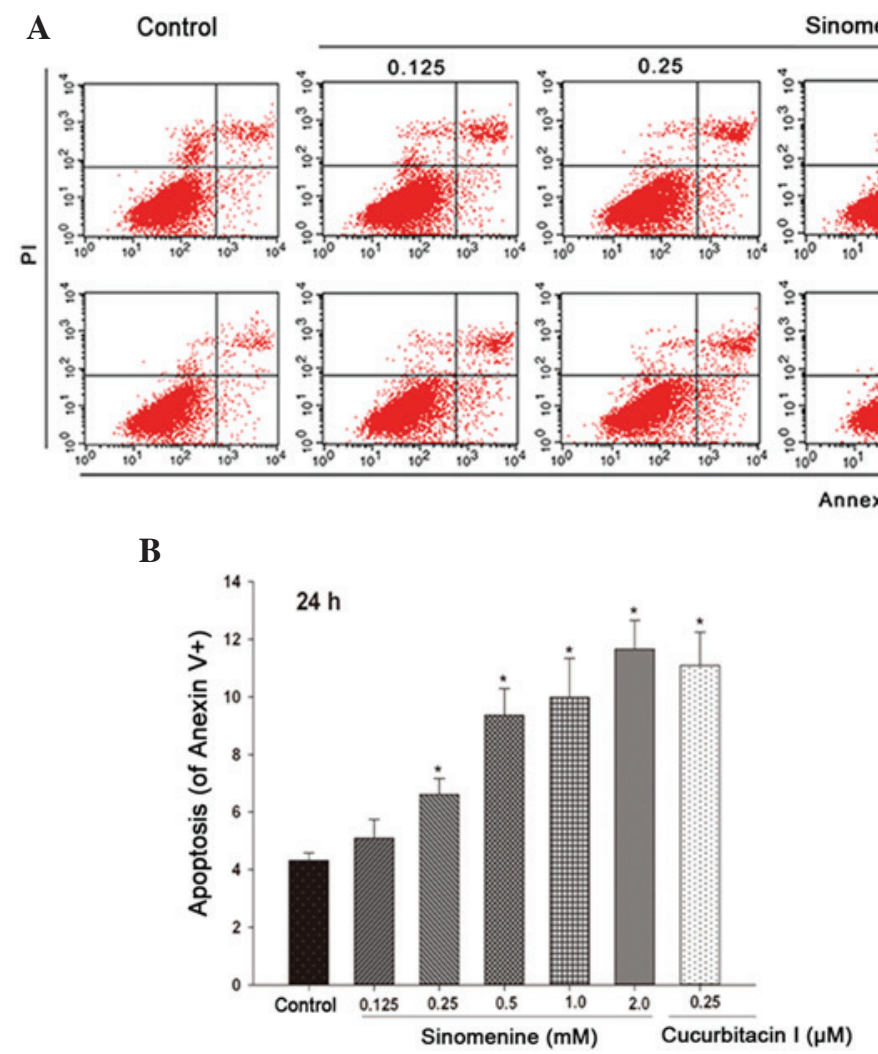

Sinomenine $(\mathrm{mM})$

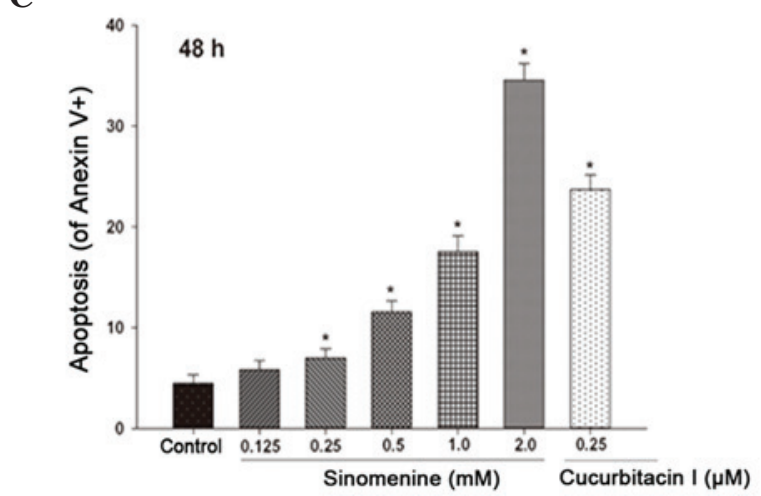

Figure 2. Effect of sinomenine on A549 cell apoptosis. A549 cells were treated with sinomenine $(0.125,0.25,0.5,1.0$ and $2.0 \mathrm{mM})$ or cucurbitacin I $(0.25 \mu \mathrm{M})$ for 24 and $48 \mathrm{~h}$, and apoptosis was measured by Annexin V/propidium iodide staining and analyzed by flow cytometry. (A) Representative scatter plots for apoptotic cells. (B) Percentage of apoptotic cells following treatment with sinomenine for $24 \mathrm{~h}$. (C) Percentage of apoptotic cells following treatment with sinomenine for $48 \mathrm{~h}$. Data are expressed as the mean \pm standard deviation $(\mathrm{n}=3)$. ${ }^{\mathrm{P}}<0.05$ vs. untreated control. PI, propidium iodide; FITC, fluorescein isothiocyanate.

biomarkers for EMT were examined by immunofluorescence. It was observed that E-cadherin staining under the plasma membrane was significantly increased in the A549 cells treated with sinomenine compared with the untreated control cells, whilst STAT3, N-cadherin and vimentin exhibited a decreased level of staining (Fig. 5). These results are consistent with the aforementioned western blotting and RT-qPCR data, and strongly suggest that sinomenine is able to attenuate A549 cell invasion through regulation of the STAT3 signaling pathway.

\section{Discussion}

The present study observed that sinomenine induced strong cytotoxicity, as indicated by decreased cell viability and apoptosis induction in A549 human lung adenocarcinoma cells. These results are consistent with previous observations in liver, breast and colon tumor cells $(13,24,25)$.

STAT3 is a key transcription factor that is widely expressed in various tissues and cell types, and is primarily activated by the JAK-STAT and mitogen-activated protein kinase signal transduction pathways (26). Increasing evidence suggests that STAT3 is involved in proliferation, differentiation, invasion, metastasis, angiogenesis and resistance to apoptosis (27). The reported abnormal upregulation of STAT3 in hematological malignancies and solid tumors, including leukemia, hepatoma, and lung, prostate and breast cancer (28-32), indicates that STAT3 is important in the pathogenesis of such tumors.

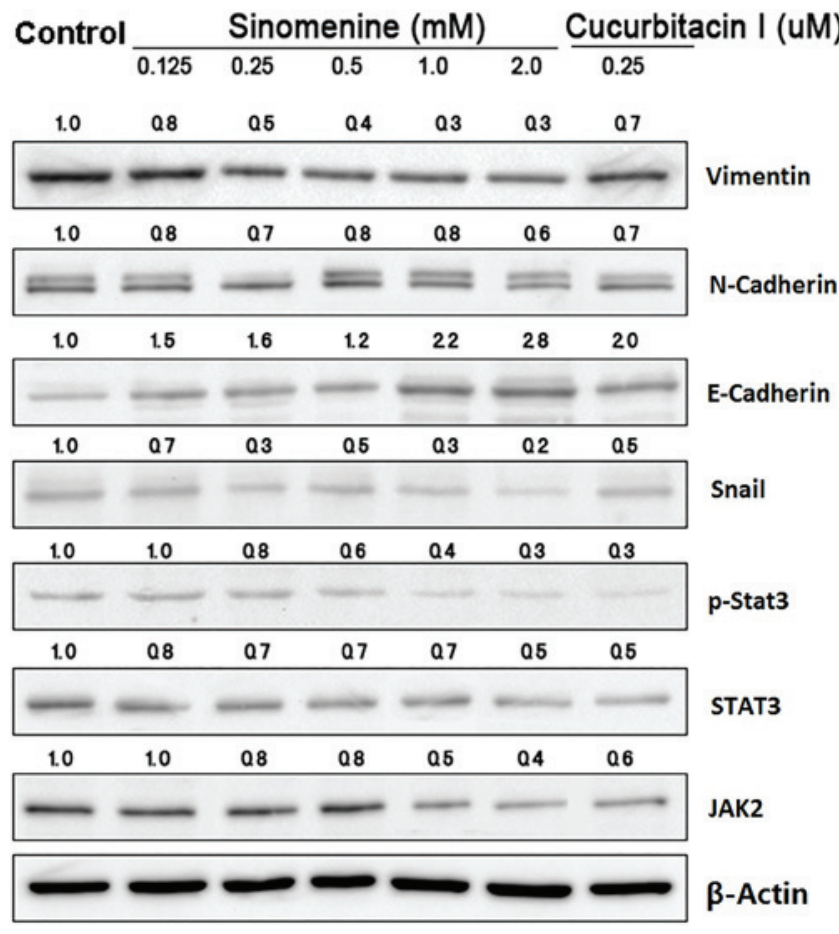

Figure 3. Effect of sinomenine on the expression of proteins involved in STAT3 signaling and EMT. Following treatment with sinomenine or cucurbitacin I for $48 \mathrm{~h}$, the expression of proteins involved in the STAT3 signal transduction pathway and EMT were analyzed by western blotting. Band densities were quantified using Image $\mathbf{J}$ and adjusted to that of the corresponding loading control. STAT3, signal transducer and activator of transcription 3; EMT, epithelial-mesenchymal transition. 
A
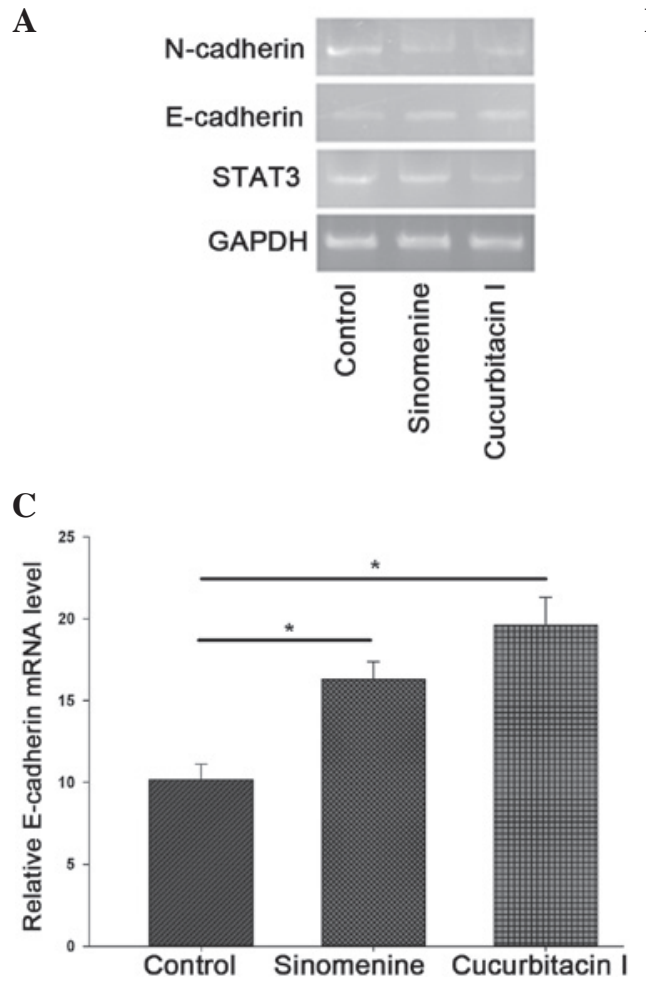

B

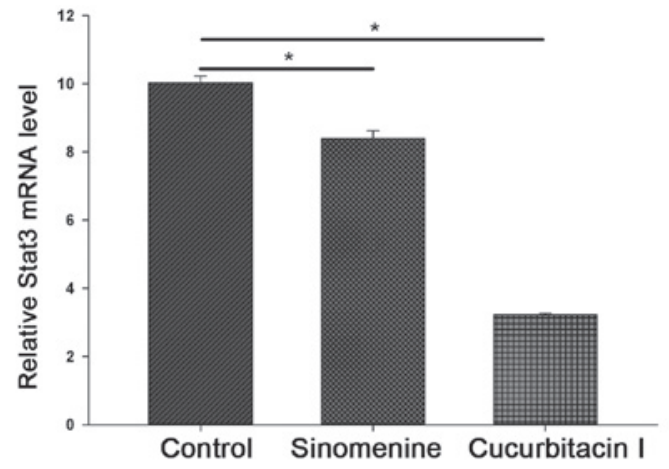

D

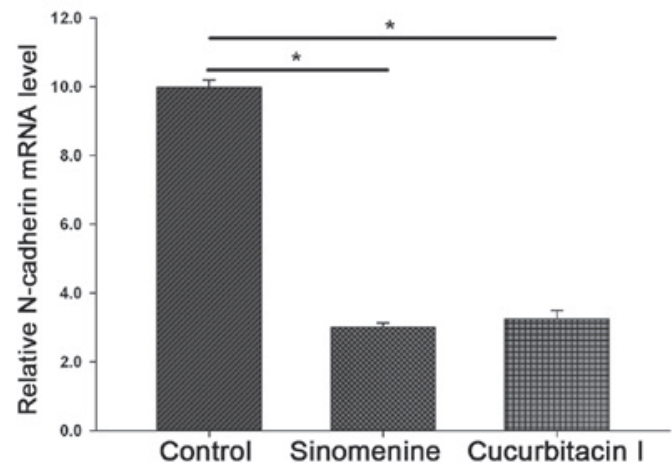

Figure 4. Effect of sinomenine on the mRNA expression of STAT3, E-cadherin and N-cadherin. A549 cells were treated with $1.0 \mathrm{mM}$ sinomenine or $0.25 \mu \mathrm{M}$ cucurbitacin I for $48 \mathrm{~h}$. Total RNA was isolated, and the mRNA expression of STAT3, E-cadherin and N-cadherin was determined by reverse transcription-quantitative polymerase chain reaction. (A) Representative agarose electrophoresis bands of N-cadherin, E-cadherin and STAT3 mRNA expression. Quantitative data of (B) STAT3, (C) E-cadherin and (D) N-cadherin gene expression. Data of three independent experiments are expressed as the mean \pm standard deviation. "P<0.05 vs. control. STAT3, signal transducer and activator of transcription 3; GAPDH, glyceraldehyde 3-phosphate dehydrogenase; mRNA, messenger RNA.
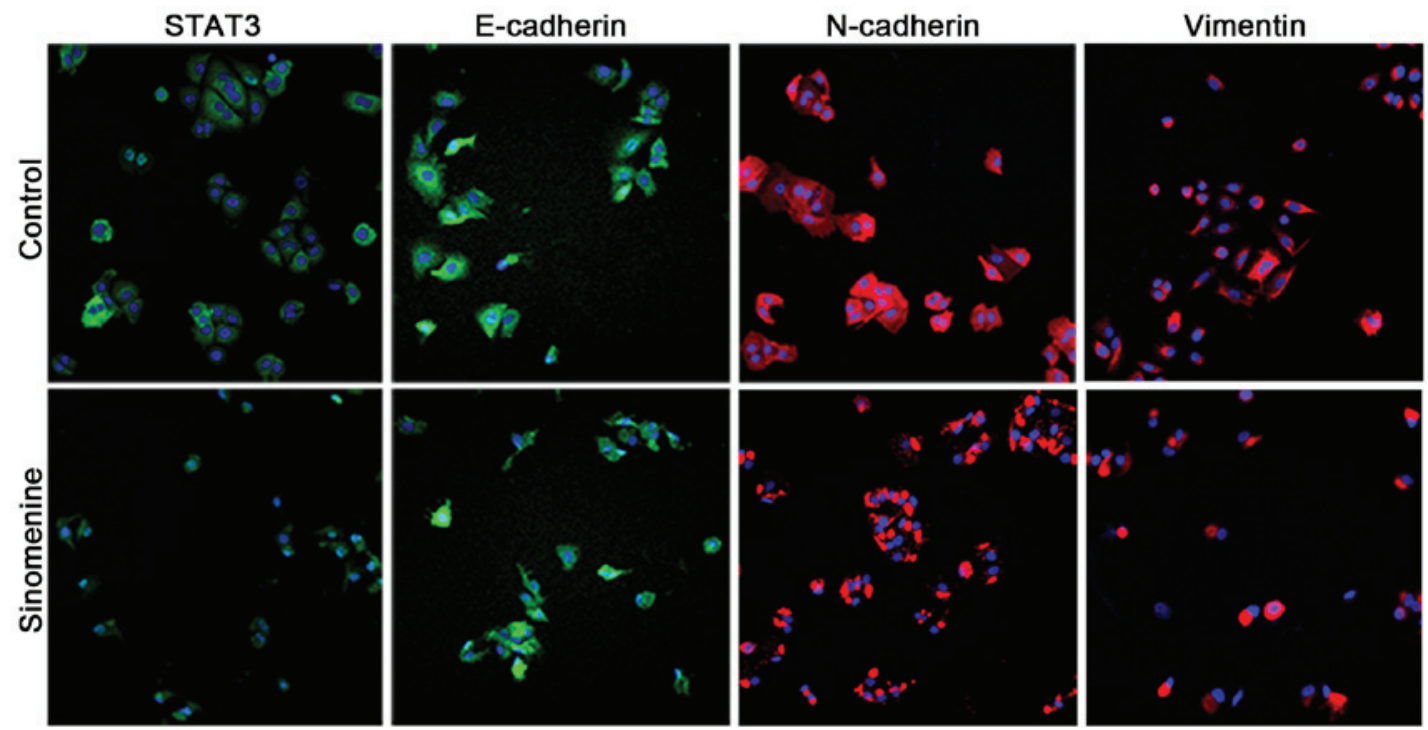

Figure 5. Immunofluorescence assay of STAT3, E-cadherin, N-cadherin and vimentin expression in A549 cells. Cells were treated with $1.0 \mathrm{mM}$ sinomenine for $24 \mathrm{~h}$. STAT3 and epithelial-mesenchymal transition markers were stained with 4',6-diamidino-2-phenylindole (blue) and anti-rabbit or anti-mouse immunoglobulin G secondary antibody conjugates (green or red), and visualized by immunofluorescence analysis (magnification, x400). STAT3, signal transducer and activator of transcription 3.

With regard to sinomenine, it has been reported that the drug possesses immunosuppressive properties, such as inhibiting the nuclear translocation of NF- $\mathrm{kB}$ (33). Notably, STAT3 and $\mathrm{NF}-\mathrm{KB}$ interact and crosstalk between their associated pathways $(34,35)$. The present study attempted to clarify whether the growth inhibition of A549 cells caused by sinomenine is mediated through the regulation of the STAT3 signaling pathway. The results demonstrated that STAT3 expression and activation were significantly suppressed in A549 cells following sinomenine treatment, which suggested that the 
inhibition of STAT3 signaling resulted in growth inhibition of A549 cells.

During the process of EMT, epithelial cells lose polarity and gain cell motility, subsequently resulting in cell invasion (36-39). A number of studies have reported that EMT is involved in tumor invasion, metastasis and chemoresistance $(36,37)$. During tumorigenesis, epithelial-type markers, including $\beta$-catenin, E-cadherin and cytokeratin, are typically downregulated, while mesenchymal markers such as $\mathrm{N}$-cadherin and vimentin are upregulated (40). Therefore, understanding how to effectively restrain the process of EMT is vital for successful treatment of cancer. In the current study, it was observed that sinomenine reversed the protein expression of EMT biomarkers, indicating that sinomenine inhibited cell invasion. In addition, sinomenine may inhibit EMT through the regulation of STAT3 and its downstream target, Snail. It has been demonstrated that STAT3 is required for EMT via upregulation of the downstream gene Snail (41). Snail is able to directly inhibit the expression of E-cadherin, and subsequently interacts with the $\mathrm{COOH}$-terminal region and the 5'-CACCTG-3' motif in the E-cadherin promoter sequence to activate EMT $(42,43)$. Yadav et al $(41)$ reported that EMT may be induced by Snail, which is activated by the JAK/STAT3 signaling pathway, in head and neck tumor cells, thus resulting in tumor metastasis.

In conclusion, the present study demonstrated that sinomenine affects apoptosis, and inhibits tumor cell death and invasion by suppressing the activation of the STAT3 signaling pathway in A549 cells. To the best of our knowledge, the present study is the first to report that sinomenine is able to reverse EMT changes in A549 cells. These results may aid the understanding of the underlying mechanisms of sinomenine in treating non-small cell lung cancer.

\section{Acknowledgements}

The current study was supported by the National Natural Science Foundation of China (Beijing, China; grant nos. 81273718 and 81403346) and the China Postdoctoral Science Foundation (Beijing, China; grant no. 2014M550132).

\section{References}

1. Yano T, Okamoto T, Fukuyama S and Maehara Y: Therapeutic strategy for postoperative recurrence in patients with non-small cell lung cancer. World J Clin Oncol 5: 1048-1054, 2014.

2. Pirker R: Adjuvant chemotherapy in patients with completely resected non-small cell lung cancer. Transl Lung Cancer Res 3 305-310, 2014.

3. Goldstraw P, Crowley J, Chansky K, Giroux DJ, Groome PA, Rami-Porta R, Postmus PE, Rusch V and Sobin L; International Association for the Study of Lung Cancer International Staging Committee; Participating Institutions: The IASLC Lung Cancer Staging Project: Proposals for the revision of the TNM stage groupings in the forthcoming (seventh) edition of the TNM Classification of malignant tumours. J Thorac Oncol 2: 706-714, 2007.

4. Byron E and Pinder-Schenck M: Systemic and targeted therapies for early-stage lung cancer. Cancer Control 21: 21-31, 2014.

5. Akbari-Birgani S, Paranjothy $T$, Zuse A, Janikowski $T$, Cieślar-Pobuda A, Likus W, Urasińska E, Schweizer F, Ghavami S, Klonisch T and $Ł o s$ MJ: Cancer stem cells, cancer-initiating cells and methods for their detection. Drug Discov Today 21: 836-842, 2016.

6. Brower V: Back to nature: Extinction of medicinal plants threatens drug discovery. J Natl Cancer Inst 100: 838-839, 2008.
7. Li JW and Vederas JC: Drug discovery and natural products: End of an era or an endless frontier? Science 325: 161-165, 2009.

8. Zhu Q, Sun Y, Zhu J, Fang T, Zhang W and Li JX: Antinociceptive effects of sinomenine in a rat model of neuropathic pain. Sci Rep 4: 7270, 2014.

9. Qian L, Xu Z, Zhang W, Wilson B, Hong JS and Flood PM: Sinomenine, a natural dextrorotatory morphinan analog, is anti-inflammatory and neuroprotective through inhibition of microglial NADPH oxidase. J Neuroinflammation 4: 23, 2007.

10. Kok TW, Yue PY, Mak NK, Fan TP, Liu L and Wong RN: The anti-angiogenic effect of sinomenine. Angiogenesis 8: 3-12, 2005.

11. Li XJ, Yue PY, Ha WY, Wong DY, Tin MM, Wang PX, Wong RN and Liu L: Effect of sinomenine on gene expression of the IL-1 beta-activated human synovial sarcoma. Life Sci 79: 665-673, 2006.

12. Jiang T, Zhou L, Zhang W, Qu D, Xu X, Yang Y and Li S: Effects of sinomenine on proliferation and apoptosis in human lung cancer cell line NCI-H460 in vitro. Mol Med Rep 3: 51-56, 2010.

13. Lu XL, Zeng J, Chen YL, He PM, Wen MX, Ren MD, Hu YN, Lu GF and He SX: Sinomenine hydrochloride inhibits human hepatocellular carcinoma cell growth in vitro and in vivo: Involvement of cell cycle arrest and apoptosis induction. Int J Oncol 42: 229-238, 2013.

14. Mantovani A, Allavena P, Sica A and Balkwill F: Cancer-related inflammation. Nature 454: 436-444, 2008.

15. Grivennikov SI, Greten FR and Karin M: Immunity, inflammation and cancer. Cell 140: 883-899, 2010.

16. Kuraishy A, Karin M and Grivennikov SI: Tumor promotion via injury- and death-induced inflammation. Immunity $35: 467-477$, 2011.

17. Karin M: Nuclear factor-kappaB in cancer development and progression. Nature 441: 431-436, 2006.

18. Yu H, Pardoll D and Jove R: STATs in cancer inflammation and immunity: A leading role for STAT3. Nat Rev Cancer 9: 798-809, 2009.

19. He G and Karin M: NF-кB and STAT3 - key players in liver inflammation and cancer. Cell Res 21: 159-168, 2011.

20. Bosch-Barrera J and Menendez JA: Silibinin and STAT3: A natural way of targeting transcription factors for cancer therapy. Cancer Treat Rev 41: 540-546, 2015.

21. Yu H, Lee H, Herrma nn A, Buettner R and Jove R: Revisiting STAT3 signalling in cancer: New and unexpected biological functions. Nat Rev Cancer 14: 736-746, 2014.

22. Wu Y, Ma G, Lu D, Lin F, Xu HJ, Liu J and Arlinghaus RB: Bcr: A negative regulator of the Bcr-Abl oncoprotein. Oncogene 18: 4416-4424, 1999.

23. Liu Z, Duan ZJ, Chang JY, Zhang ZF, Chu R, Li YL, Dai KH, Mo GQ and Chang QY: Sinomenine sensitizes multidrug-resistant colon cancer cells (Caco-2) to doxorubicin by downregulation of MDR-1 expression. PLoS One 9: e98560, 2014.

24. Li X, Wang K, Ren Y, Zhang L, Tang XJ, Zhang HM, Zhao CQ, Liu PJ, Zhang JM and He JJ: MAPK signaling mediates sinomenine hydrochloride-induced human breast cancer cell death via both reactive oxygen species-dependent and -independent pathways: An in vitro and in vivo study. Cell Death Dis 5: e1356, 2014.

25. Zhang JX, Yang ZR, Wu DD, Song J, Guo XF, Wang J and Dong WG: Suppressive effect of sinomenine combined with 5 -fluorouracil on colon carcinoma cell growth. Asian Pac J Cancer Prev 15: 6737-6743, 2014.

26. Spitzner M, Ebner R, Wolff HA, Ghadimi BM, Wienands J and Grade M: STAT3: A novel molecular mediator of resistance to chemoradiotherapy. Cancers (Basel) 6: 1986-2011, 2014.

27. Siveen KS, Sikka S, Surana R, Dai X, Zhang J, Kumar AP, Tan BK, Sethi G and Bishayee A: Targeting the STAT3 signaling pathway in cancer: Role of synthetic and natural inhibitors. Biochim Biophys Acta 1845: 136-154, 2014.

28. Ishida F, Matsuda K, Sekiguchi N, Makishima H, Taira C, Momose K, Nishina S, Senoo N, Sakai H, Ito T and Kwong YL: STAT3 gene mutations and their association with pure red cell aplasia in large granular lymphocyte leukemia. Cancer Sci 105: 342-346, 2014.

29. Geletu M, Guy S and Raptis L: Effects of SRC and STAT3 upon gap junctional, intercellular communication in lung cancer lines. Anticancer Res 33: 4401-4410, 2013.

30. Ramakrishna G, Rastogi A, Trehanpati N, Sen B, Khosla R and Sarin SK: From cirrhosis to hepatocellular carcinoma: New molecular insights on inflammation and cellular senescence. Liver Cancer 2: 367-383, 2013. 
31. Hsu FN, Chen MC, Lin KC, Peng YT, Li PC, Lin E, Chiang MC, Hsieh JT and Lin H: Cyclin-dependent kinase 5 modulates STAT3 and androgen receptor activation through phosphorylation of $\mathrm{Ser}^{727}$ on STAT3 in prostate cancer cells. Am J Physiol Endocrinol Metab 305: E975-E986, 2013.

32. Ibrahim SA, Hassan H, Vilardo L, Kumar SK, Kumar AV, Kelsch R, Schneider C, Kiesel L, Eich HT, Zucchi I, et al: Syndecan-1 (CD138) modulates triple-negative breast cancer stem cell properties via regulation of LRP-6 and IL-6-mediated STAT3 signaling. PLoS One 8: e85737, 2013.

33. Zhao Y, Li J, Yu K, Liu Y and Chen X: Sinomenine inhibits maturation of monocyte-derived dendritic cells through blocking activation of NF-kappa B. Int Immunopharmacol 7: 637-645, 2007.

34. De Simone V, Franzè E, Ronchetti G, Colantoni A, Fantini MC, Di Fusco D, Sica GS, Sileri P, MacDonald TT, Pallone F, et al: Th17-type cytokines, IL- 6 and TNF- $\alpha$ synergistically activate STAT3 and NF- $\kappa$ B to promote colorectal cancer cell growth. Oncogene 34: 3493-3503, 2015.

35. Levy DE and Darnell JE Jr: Stats: Transcriptional control and biological impact. Nat Rev Mol Cell Biol 3: 651-662, 2002.

36. Rho JK, Choi YJ, Lee JK, Ryoo BY, Na II, Yang SH, Kim CH and Lee JC: Epithelial to mesenchymal transition derived from repeated exposure to gefitinib determines the sensitivity to EGFR inhibitors in A549, a non-small cell lung cancer cell line. Lung Cancer 63: 219-226, 2009.
37. Ceppi P, Mudduluru G, Kumarswamy R, Rapa I, Scagliotti GV, Papotti $M$ and Allgayer H: Loss of miR-200c expression induces an aggressive, invasive, and chemoresistant phenotype in non-small cell lung cancer. Mol Cancer Res 8: 1207-1216, 2010.

38. Micalizzi DS, Farabaugh SM and Ford HL: Epithelial-mesenchymal transition in cancer: Parallels between normal development and tumor progression. J Mammary Gland Biol Neoplasia 15: 117-134, 2010

39. Thiery JP, Acloque H, Huang RY and Nieto MA: Epithelial-mesenchymal transitions in development and disease. Cell 139: 871-890, 2009.

40. Tiwari N, Gheldof A, Tatari M and Christofori G: EMT as the ultimate survival mechanism of cancer cells. Semin Cancer Biol 22: 194-207, 2012.

41. Yadav A, Kumar B, Datta J, Teknos TN and Kumar P: IL-6 promotes head and neck tumor metastasis by inducing epithelial-mesenchymal transition via the JAK-STAT3-SNAIL signaling pathway. Mol Cancer Res 9: 1658-1667, 2011.

42. Peinado H, Portillo F and Cano A: Transcriptional regulation of cadherins during development and carcinogenesis. Int J Dev Biol 48: 365-375, 2004.

43. Cano A, Pérez-Moreno MA, Rodrigo I, Locascio A, Blanco MJ, del Barrio MG, Portillo F and Nieto MA: The transcription factor snail controls epithelial-mesenchymal transitions by repressing E-cadherin expression. Nat Cell Biol 2: 76-83, 2000. 